\title{
Fathers bequeath more mutations as they age
}

\section{Genome study may explain links between paternal age and conditions such as autism.}

\section{BY EWEN CALLAWAY}

I $\mathrm{n}$ the 1930s, the pioneering geneticist J. B. S. Haldane noticed a peculiar inheritance pattern in families with long histories of haemophilia. The faulty mutation responsible for the bloodclotting disorder tended to arise on the $\mathrm{X}$ chromosomes that fathers passed to their daughters, rather than on those that mothers passed down. Haldane subsequently proposed ${ }^{1}$ that children inherit more mutations from their fathers than their mothers, although he acknowledged that "it is difficult to see how this could be proved or disproved for many years to come".

That year has finally arrived: wholegenome sequencing of dozens of Icelandic families has at last provided the evidence that eluded Haldane. Moreover, a study published in Nature finds that the age at which a father sires children determines how many mutations those offspring inherit ${ }^{2}$. By starting families in their thirties, forties and beyond, men could be increasing the chances that their children will develop autism, schizophrenia and other diseases often linked to new mutations. "The older we are as fathers, the more likely we will pass on our mutations," says lead author Kári Stefánsson, chief executive of deCODE Genetics in Reykjavik. "The more mutations we pass on, the more likely that one of them is going to be deleterious."

Haldane, working years before the structure of DNA was determined, was also correct about why fathers pass on more mutations. Sperm is continually being generated by dividing precursor cells, which acquire new mutations with each division. By contrast, women are born with their lifelong complement of egg cells.

Stefánsson, whose company maintains genetic information on most Icelanders, compared the whole-genome sequences of 78 trios of a mother, father and child. The team searched for mutations in the child that were not present in either parent and that must therefore have arisen spontaneously in the egg, sperm or embryo. The paper reports the largest such study of nuclear families so far.

Fathers passed on nearly four times as

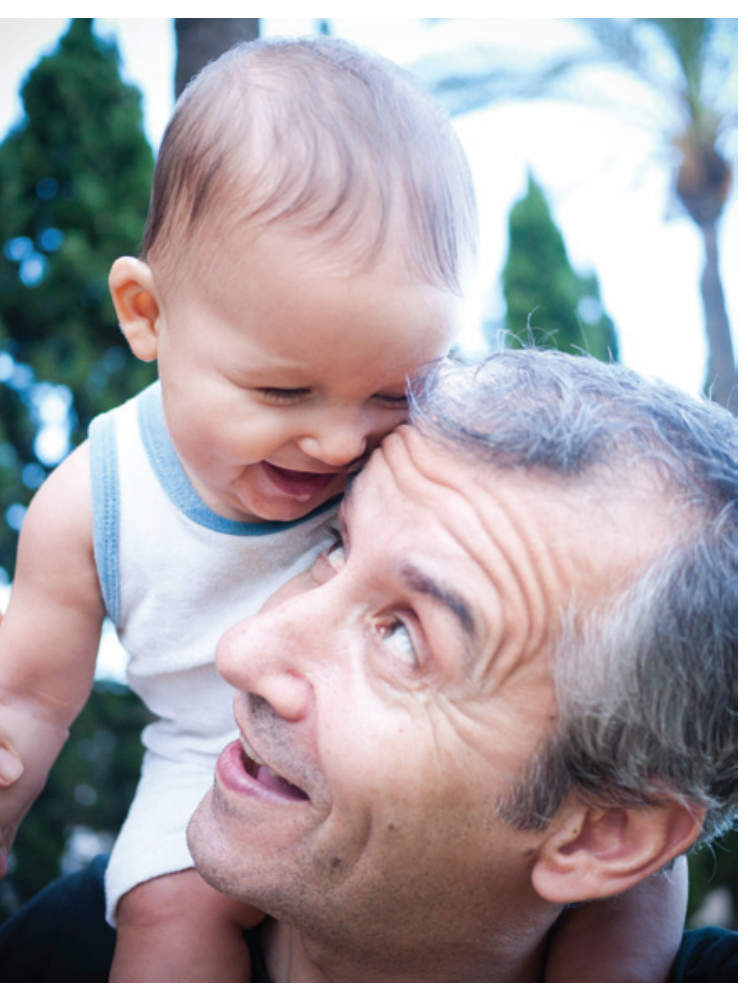

Older fathers' sperm have more mutations — as do their children.

Stefánsson and other geneticists say.

Previous studies have shown that a child's risk of being diagnosed with autism increases with the father's age. And a trio of papers ${ }^{3-5}$ published this year identified dozens of new mutations implicated in autism and found that the mutations were four times more likely to originate on the father's side than the mother's.

The results might help to explain the apparent rise in autism spectrum disorder: this year, the US Centers for Disease Control and Prevention in Atlanta, Georgia, reported that one in every 88 American children has now been diagnosed with autism spectrum disorder, a 78\% increase since 2007. Better and more inclusive autism diagnoses explain some of this increase, but new mutations are probably also a factor, says Daniel Geschwind, a neurobiologist at the University of California, Los Angeles. "I think we will find, in places where there are really old dads, higher prevalence of autism."

However, Mark Daly, a geneticist at Massachusetts General Hospital in Boston who studies autism, says that many new mutations as mothers: on average, 55 versus 14 . The father's age also accounted for nearly all of the variation in the number of new mutations in a child's genome, with the number of new mutations being passed on rising exponentially with paternal age. A 36-yearold will pass on twice as many mutations to his child as a man of 20, and a 70-year-old eight times as many, Stefánsson's team estimates.

The researchers estimate that an Icelandic child born in 2011 will harbour 70 new mutations, compared with 60 for a child born in 1980; the average age of fatherhood rose from 28 to 33 over that time.

Most such mutations are harmless, but Stefánsson's team identified some that studies have linked to conditions such as autism and schizophrenia. The study does not prove that
ONATURE.COM Hear more about this research on the Nature Podcast: go.nature.com/Iq2dhy older fathers are more likely than younger ones to pass on disease-associated or other deleterious genes, but that is the strong implication, increasing paternal age is unlikely to account for all of the rise in autism prevalence. $\mathrm{He}$ notes that autism is highly heritable, but that most cases are not caused by a single new mutation - so there must be predisposing factors that are inherited from parents but are distinct from the new mutations occurring in sperm.

Historical evidence suggests that older fathers are unlikely to augur a genetic meltdown. Throughout the seventeenth and eighteenth centuries, Icelandic men fathered children at much higher ages than they do today, averaging between 34 and 38. Moreover, genetic mutations are the basis for natural selection, Stefánsson points out. "You could argue what is bad for the next generation is good for the future of our species," he says. SEE NEWS AND VIEWS, P467 AND ARTICLE, P471

1. Haldane, J. B. S. Ann. Eugen. 13, 262-271 (1947).

2. Kong, A. et al. Nature $\mathbf{4 8 8 , 4 7 1 - 4 7 5 ~ ( 2 0 1 2 ) . ~}$

3. Sanders, S. J. et al. Nature 485, 237-241 (2012).

4. O'Roak, B. J. et al. Nature 485, 246-250 (2012).

5. Neale, B. M. et al. Nature 485, 242-245 (2012). 